\title{
Efficacy of Granulocytapheresis for the Treatment of Active Ulcerative Colitis and Avoidance of Systemic Corticosteroid Administration
}

\author{
Chikako Tokoro ${ }^{a}$ Masahiko Inamori ${ }^{a}$ Takasi Uchiyama ${ }^{a}$ Hiroshi lida $^{a}$ Hiroki Endo $^{a}$

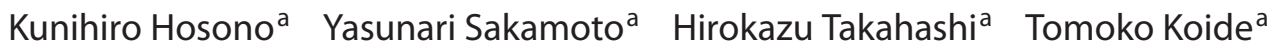 \\ Ayumu Goto $^{a}$ Hiroaki Yasuzaki ${ }^{a}$ Yasunobu Abe ${ }^{a}$ Reikei Matsuda ${ }^{b}$ Daisuke Takahashi ${ }^{b}$ \\ Ichiro Kawana $^{a}$ Shinichiro Suzuki ${ }^{b}$ Atsushi Nakajima ${ }^{a}$ \\ ${ }^{a}$ Gastroenterology Division, Yokohama City University Hospital, and b Department of Gastroenterology, \\ Fujisawa Shounandai Hospital, Yokohama, Japan
}

Dear Sir,

The infiltration of granulocytes into the colonic mucosa plays an important role in the pathogenesis of ulcerative colitis (UC), and the removal of granulocytes may be a logical therapeutic strategy. Granulocytapheresis (GCAP) is a new technique that removes a significant amount of circulating granulocytes, reducing their migration into the intestinal mucosa [1-3]. The aim of this study was to evaluate the efficacy of GCAP in outpatients with active UC prior to the administration of systemic corticosteroids, which is the standard treatment for moderate to severe UC but which sometimes causes serious adverse effects.

We enrolled 16 consecutive outpatients (7 women and 9 men; age range 22-57 years) with UC who exhibited signs of acute disease but had not yet received systemic corticosteroid treatment. The disease activity was evaluated using the clinical activity index (CAI; Truelove-Witts criteria) [4]. All the patients received 5 or 10 GCAP treatments (1 treatment/week). We evaluated the patients' statuses before and after completion of GCAP therapy.

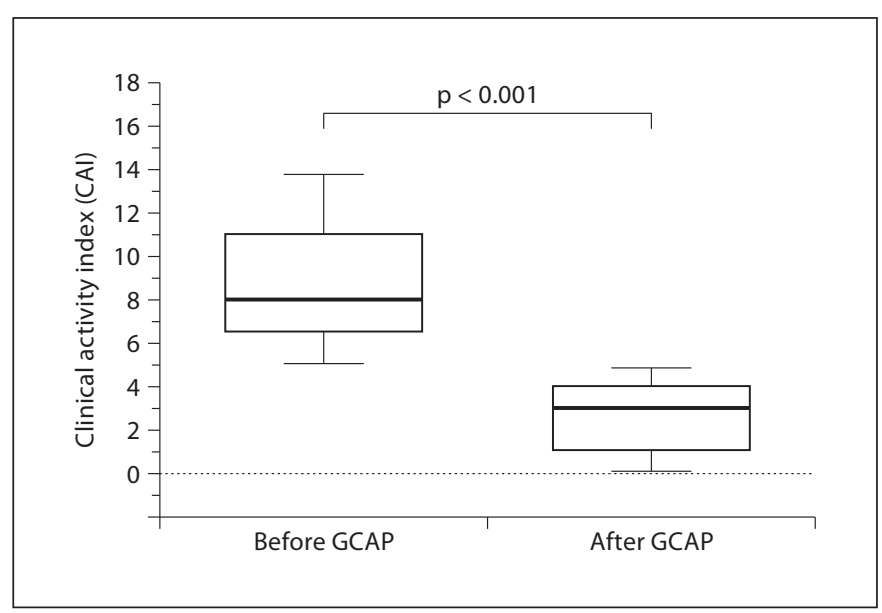

Fig. 1. The median clinical activity index (range) decreased from $8(5-16)$ to $3(0-5) . p<0.001$, Wilcoxon signed-rank test.

All the patients had active colitis at baseline. The median CAI (range) decreased from $8(5-16)$ to $3(0-5 ; \mathrm{p}<0.001$, Wilcoxon signed-rank test; fig. 1). All the patients completed the GCAP therapy without experiencing severe adverse effects. Only a transient mild headache was recorded in 1 patient during the procedure. After GCAP treatment, 9 patients (56.3\%) achieved remission defined as a

\section{KARGER}

Fax +41613061234 E-Mail karger@karger.ch www.karger.com www.karger.com/dig
M. Inamori, $\mathrm{MD}, \mathrm{PhD}$

Gastroenterology Division, Yokohama City University Hospita

3-9 Fukuura, Kanazawa-ku

Yokohama 236-0004 (Japan)

Tel. +81 45787 2640, Fax +81 45784 3546, E-Mail inamorim@med.yokohama-cu.ac.jp 
CAI of $<5$, and 5 patients (31.3\%) exhibited a partial response defined as a CAI of -3 or greater without remission. Finally, $14 \mathrm{pa}-$ tients (87.5\%) achieved clinical remission without receiving systemic corticosteroid treatment.
In conclusion, our study revealed that GCAP is safe and enables the avoidance of systemic corticosteroid administration in patients with active UC. GCAP may improve the quality of life of patients with active UC, but this issue remains controver- sial [1-3]. Further prospective rigorous and appropriately designed clinical trials with established end points and doubleblinded studies are needed to confirm this assumption.
References
1 Bresci G, Parisi G, Mazzoni A, Scatena F, Capria A: Granulocytapheresis versus methylprednisolone in patients with acute ulcerative colitis: 12-month follow up. J Gastroenterol Hepatol 2008;23:1678-1682.

2 Sands BE, Sandborn WJ, Feagan B, et al: A randomized, double-blind, sham-controlled study of granulocyte/monocyte apheresis for active ulcerative colitis. Gastroenterology 2008;135:400-409.
3 Sakuraba A, Motoya S, Watanabe K, et al: An open-label prospective randomized multicenter study shows very rapid remission of ulcerative colitis by intensive granulocyte and monocyte adsorptive apheresis as compared with routine weekly treatment. Am J Gastroenterol 2009;104:2990-2995.

4 Lichtiger S, Present DH, Kornbluth A, et al: Cyclosporine in severe ulcerative colitis refractory to steroid therapy. N Engl J Med 1994;330:1841-1845. 